\title{
Powder interlayer bonding of geometrically complex Ti-6Al-4V parts
}

\author{
I. T. Watkins ${ }^{1}$ (I) $\cdot$ H. M. Davies ${ }^{1}$ - O. G. Stanners ${ }^{1}$ - S. Marchisio ${ }^{2}$ \\ Received: 27 August 2019 / Accepted: 10 November 2019/Published online: 20December 2019 \\ (C) The Author(s) 2020
}

\begin{abstract}
Powder interlayer bonding (PIB) is a novel joining technique, which has been developed to facilitate high-integrity repairs of aerospace components, manufactured from commonly used titanium alloys. The PIB technique utilises an interlayer between complex geometric components which are mated under pressure and a highly localised heating source. In this study, induction heating enabled bonding in an inert fusion zone by use of an oxygen-displacing shielding gas, with particular attention to the initial heating and pressure application. These early stages proved crucial to the elimination of pores and consolidation of the alloy powder, with porosity volume fraction reduced to just $0.5 \%$ after just $20 \mathrm{sec}$ at the bonding force. The technique has produced high-integrity bonds in alloys such as Ti-6Al-4V, retaining approximately $90 \%$ of the alloy strength in previous studies, offering advantages over established joining methods such as tungsten inert gas (TIG) and plasma arc (PA) welding due to a more highly localised heating and fusion zone. It is believed that powder interlayer bonding can compete against these techniques, providing a more time and costeffective repair route for net shape components manufactured from a range of alloys with minimal post-processing.
\end{abstract}

Keywords Powder interlayer bonding (PIB) · Ti-6-4 · Complex geometry · Titanium powder · Repair

\section{Introduction}

Titanium has historically been a key material in the development of the gas turbine industry over the last 75 years and is extensively used in gas turbine applications [1]. One of the largest factors to the success of titanium for gas turbine applications is its high strength to weight ratio when compared to other materials. Elemental titanium has a density of just $4.5 \mathrm{~g} \cdot \mathrm{cm}^{-3}$ compared to $7.86 \mathrm{~g} \cdot \mathrm{cm}^{-3}$ for iron, while also exhibiting a tensile strength of $440 \mathrm{MPa}$ compared to the $340 \mathrm{MPa}$ of iron. As a result, titanium alloys currently make up approximately $30 \%$ of the weight of gas turbine engines and are still extensively researched in order to maximise further improvements and efficiency gains [1]. This impressive strength to weight ratio negates the added cost of using titanium as opposed to steel turbine compressor and fan assemblies [2] due to the fuel cost savings made over the lifespan of the engine. The high level of centrifugal loading of these front sections of the engine also utilises the

I. T. Watkins

919341@ swansea.ac.uk

1 Institute of Structural Materials, College of Engineering, Bay Campus, Swansea University, Swansea SA1 8EN, UK

2 Rolls-Royce plc, Box 31, Derby, PO DE24 8BJ, UK high stiffness of titanium, which has a Young's modulus E of 120 $\mathrm{GPa}$ [3]. Additionally, the microstructure of titanium alloys is easily manipulated by thermo-mechanical processing; meaning a wide range of alloy variants can be suited to different applications within the engine [4]. The microstructures of Ti alloys are described according to the distribution of its two phases, alpha $(\alpha)$ and beta $(\beta)$. The morphology of the $\beta$-phase can also be manipulated for further refinement of microstructural properties, by either cooling from the $\beta$-phase region to produce a lamellar structure or by making use of recrystallisation mechanisms through hot working to produce an equiaxed structure [5]. Due to the acceptable combination of low-density and high-strength fatigue performance at ambient temperatures, $\alpha+\beta$-alloys such as Ti 6-4 are typically used in the low-pressure compressor and fan blade assemblies of gas turbine engines, with highertemperature capability alloys such as Ti-6246 being used in hotter sections such as the high-pressure compressor [6].

Ti 6-4 is the most extensively used alloy for fan and compressor applications, as well as for static structures such as casings and instrumentation mounting bosses, due to its reasonable strength of $\sim 1050 \mathrm{MPa}$ and fatigue strength of $500 \mathrm{MPa}$ at $10^{7}$ cycles at room temperature [7]. The temperature at which the $\beta$-field separates from the $\alpha+\beta$-region is called the beta transus $\left(\beta^{T}\right)$ and is around $996{ }^{\circ} \mathrm{C} 14{ }^{\circ} \mathrm{C}$ for Ti 6-4 [7]. This means Ti 6-4 excellent feasibility for heat treatment manipulation of the microstructure [8]. Aluminium is included as a solid solution 


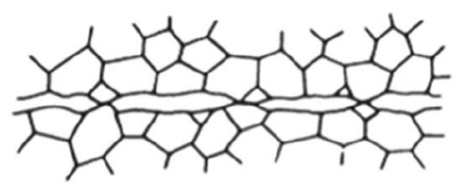

INITIAL ASPERITY CONTACT
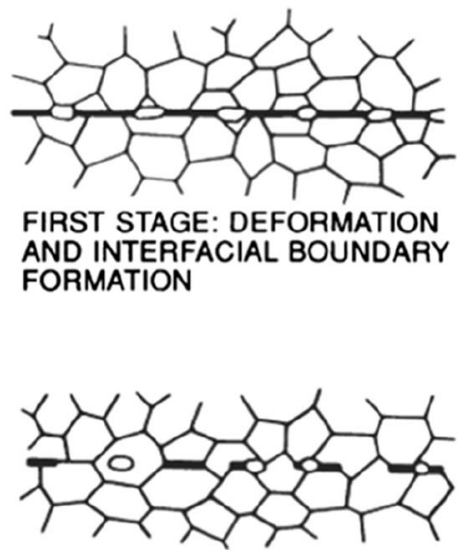

SECOND STAGE: GRAIN BOUNDARY MIGRATION AND PORE ELIMINATION

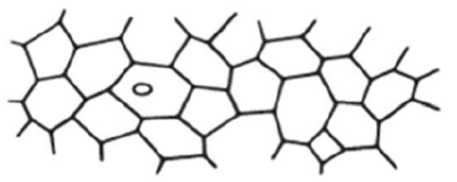

VOLUME DIFFUSION AND PORE ELIMINATION

Fig. 1 Diffusion bonding schematic [18] strengthening $\alpha$-stabiliser at $6 \mathrm{wt}$. $\%$, as well as vanadium at 4 wt. $\%$ as a $\beta$-stabiliser. Including a $\beta$-stabiliser in this concentration exceeds the solubility limit of the $\alpha$-phase at all temperatures, allowing some retained $\beta$-phase at room temperature [9].

As environmental concerns continue to drive the need for gas turbine efficiency improvements, designers are increasingly looking for ways to reduce the weight of engines and components. One example is in low-pressure compressor sections, which have previously consisted of individual Ti 6-4 blades slotted into a dovetail disc assembly. These are now being manufactured by linear friction welding [10] as solid one-piece components known as bladed discs (blisks) [11]. While this provides weight savings of up to $30 \%$ when compared to compressor assemblies, this presents a significant issue concerning components damaged in service, as replacing individual blades is no longer possible and costly scrappages of entire components need to be avoided wherever possible [12]. However, both the large size and geometric complexity of these components mean that repair is far more difficult than in multiple-component assemblies, especially when you consider the need to retain the microstructure and limit heat damage in the region surrounding the repair.

For this reason, liquid-state welding processes such as tungsten inert gas (TIG), plasma arc (PA) and laser beam (LB) welding [13] would not be suitable for safety critical repairs in components such as blisks. This is due to the large heat-affected zone (HAZ), as heating to the liquid state not only produces a significant amount of defects and deformation

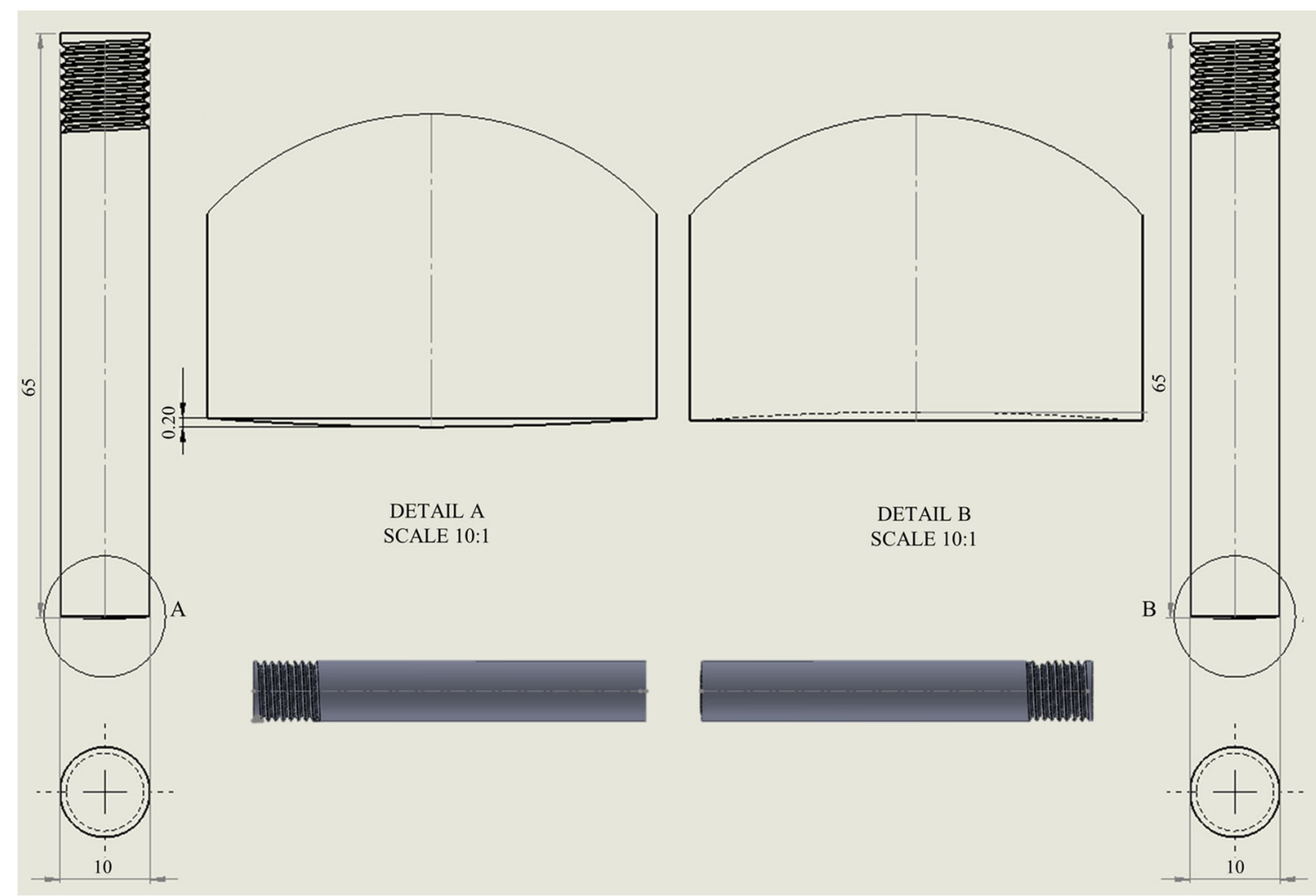

Fig. 2 0.2-mm 'cup and coned' specimen geometry 


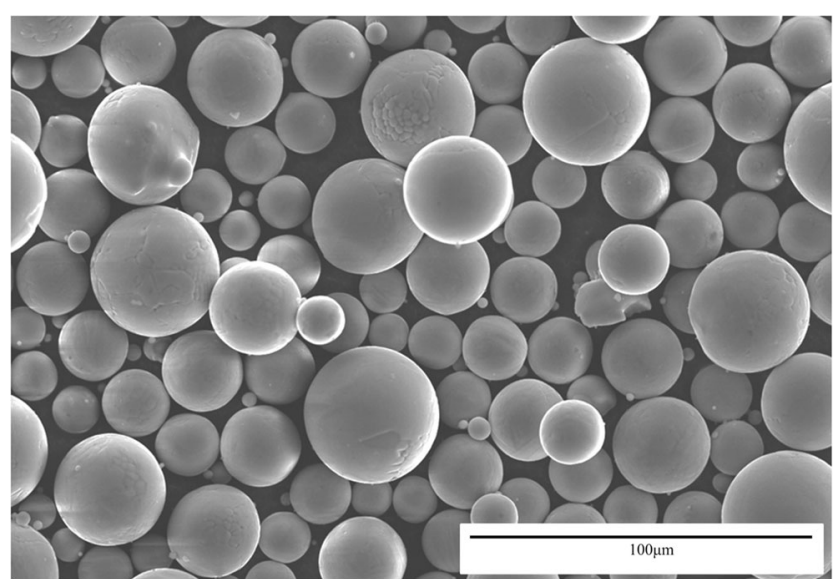

Fig. 3 SEM micrograph of Ti 6-4 gas atomised powder used

upon cooling [14] but also causes transformation of the Ti 6-4 microstructure above the $\beta^{T}$. These transformed regions can have a significantly larger grain size compared to the base material, which is undesirable. It is hoped that diffusion-reliant, solid-state welding processes could provide a viable route into the exploration of repair options for components such as these, as they can be performed at much lower temperatures, producing less defects and deformation. Rolls-Royce plc already uses diffusion bonding as a manufacturing process for wide chord fan blades in their Trent range of engines [15].

Since diffusion bonding causes little/no changes to mechanical properties of the parent material, there is usually very little need for post-weld heat treatment, especially given the small heat-affected zone when resistance or induction heating methods are employed [15]. Thus, diffusion bonding has been widely used to join Ti alloys including Ti 6-4 alloy [16-22]. A schematic of the diffusion bonding process is shown in Fig. 1. Given the relatively cool bonding temperatures, the minimal shrinkage on cooling also results in very low residual stresses in the bonded component, especially when compared to fusional weld processes carried out above the melting temperature of the parent material. However, the need to control the environment, temperature and pressure for extended periods of bonding requires highly specialised equipment, and as such, diffusion bonding comes at the expense of largely inflated equipment and processing costs [23]. The justification of these costs is far easier in the aerospace component industry, where maximising the safety of components comes before the minimisation of costs; however, the detail of preparation and precision required for the process

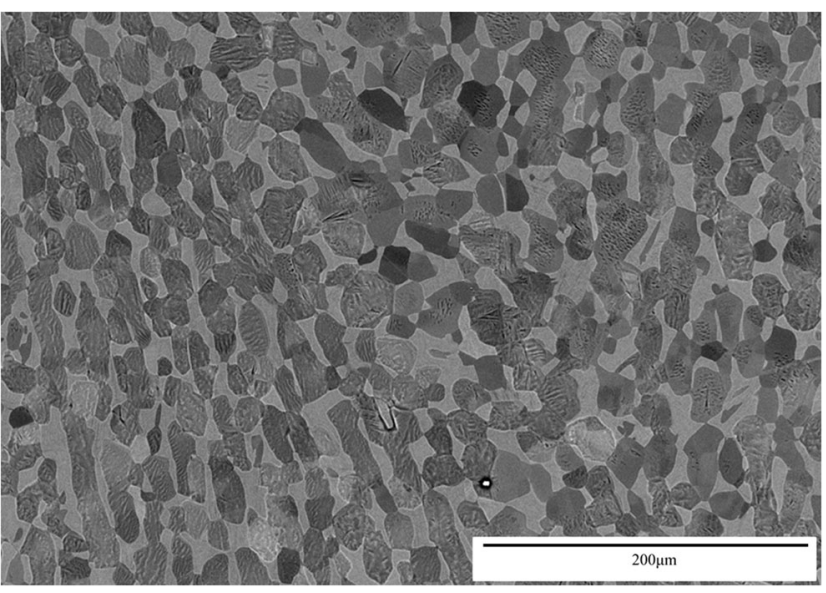

Fig. 4 SEM BSE micrograph of Ti 6-4 billet material used for specimen production

does not suit itself particularly well to larger-scale manufacturing processes. However, the naturally smaller-scale implementation as a repair process is entirely feasible, albeit with certain caveats regarding the significant time costs involved with repair processes relying on diffusion to fully close asperities between two faying surfaces [24].

Powder interlayer bonding is a hybrid solid-state welding technique, employing aspects of both diffusion bonding and diffusion brazing [25]. While a powder filler material is used to fill the voids between microscopic asperities between the mating surfaces for powder interlayer bonding, it differs from diffusion brazing in that the filler material is never raised above its melting temperature and is made of the same alloy as at least one of the parent materials. This means that the bonding process is entirely solid state and involves pure diffusion of atoms between the alloy powder and both substrates to produce cohesion. Utilisation of powder material to fill the asperities between the bonding surfaces increases the diffusional contact area and hence decreases process time. This can allow bonding of geometries that simply would not be possible by traditional diffusion bonding or diffusion brazing, as the powder material can be easily shaped to promote adhesion of surfaces with complex geometries, without introducing any new atoms into the bonded component. This comes with the advantage of being able to utilise higher pressures for bonding in order to promote integrity, with less deformation of the bulk material. It is hoped that powder interlayer bonding could provide a viable repair option for static structure (casing) and blisk repair, whereby any damaged

Table 1 Interrupted bonding regimes tested

\begin{tabular}{llllll}
\hline & $\begin{array}{l}\text { Temperature } \\
(\mathbf{C})\end{array}$ & $\begin{array}{l}\text { Temperature ramp rate } \\
\mathbf{(} \mathbf{C} / \mathbf{s})\end{array}$ & $\begin{array}{l}\text { Holding force } \\
(\mathbf{k N})\end{array}$ & $\begin{array}{l}\text { Bonding force } \\
\mathbf{( k N )}\end{array}$ & $\begin{array}{l}\text { Air cooling force } \\
(\mathbf{k N})\end{array}$ \\
\hline Bond 1 & 850 & 5 & 0.2 & 0.2 & 0.2 \\
Bond 2 & 940 & 5 & 0.2 & 0.2 & 0.2 \\
Bond 3 & 940 & 5 & 0.2 & 3.2 & 0.2 \\
Bond 4 & 940 & 5 & 0.2 & 3.2 & 0.2 \\
\hline
\end{tabular}


Fig. 5 Graph detailing length upset by bond iteration

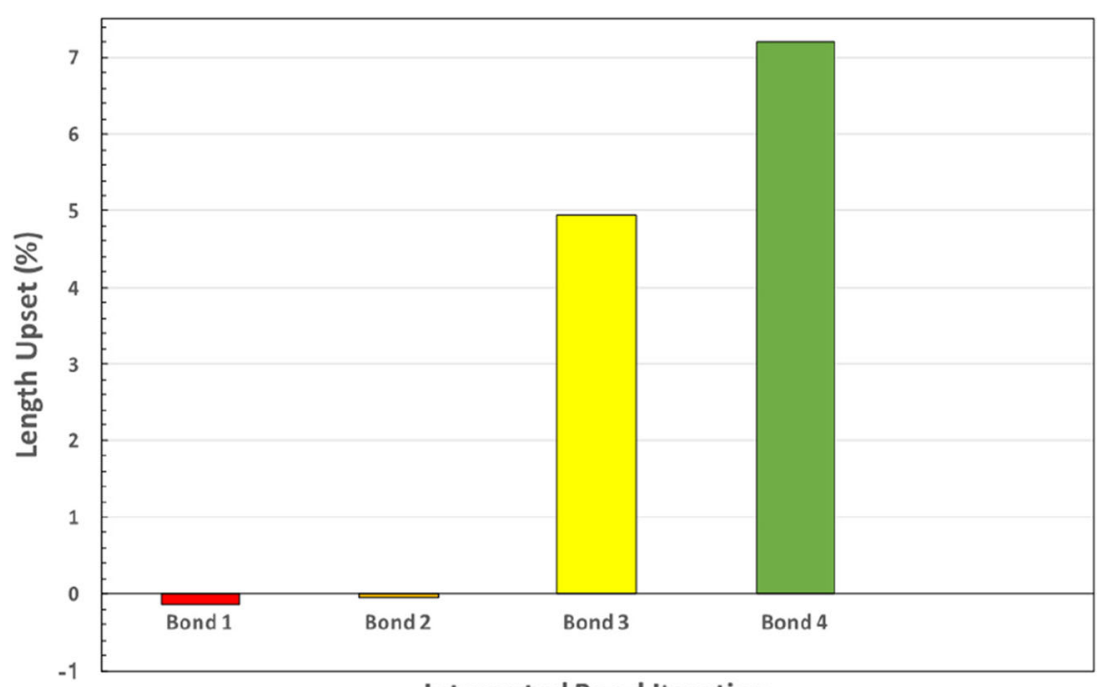

Interupted Bond Iteration blades can simply be removed and a new one bonded back in its place. Previous investigations of powder interlayer bonding of Ti 6-4 with Ti 6-4 interlayers have shown excellent promise, with bonds retaining $90 \%$ of the strength of the base material with comparable ductility [26].

In this body of work, a greater understanding of the powder collapse mechanics during the early stages of bonding was assessed using Ti 6-4-mated curved geometric specimens with a Ti 6-4 powder interlayer. Early powder interlayer bonding research programmes initially concentrated on the bonding of plain faying surfaces between similar and dissimilar structural aerospace alloys [27]. SEM examination of bonds produced by these programmes has exhibited a limited amount of bondline porosity, with small amounts of contamination. Despite this, very reasonable mechanical properties are attainable, and fatigue testing has often resulted in fractures in the parent material rather than interlayer region [28]. This demonstrates the importance of careful control of interlayer application and bonding process itself in order to prevent contamination, while the need to minimise defects in the interlayer region suggests that thinner and more refined powders may be more applicable in the bonding of similar metals.

This theory also has some support in the findings of hot isostatic pressing (HIP) investigations carried out on Ti alloy powders [29], which showed that low cycle fatigue tolerance to defects is controlled by defect size and location. This further reinforces the need to take care to avoid contaminant inclusions which can function as initiation sites. Since powder interlayer bonding relies on consolidation of metallic powders under pressure much like HIPing, it seems logical that higher pressures and longer bond times are likely to promote powder consolidation and reduce the size and frequency of defects. However, unlike HIPing, due to the nature of diffusion bonding geometries, a natural trade-off exists in terms of optimising the correct combination of powder consolidation and plastic deformation (upset) in the bond region [27]. Since
Fig. 6 Graph detailing diameter upset by bond iteration

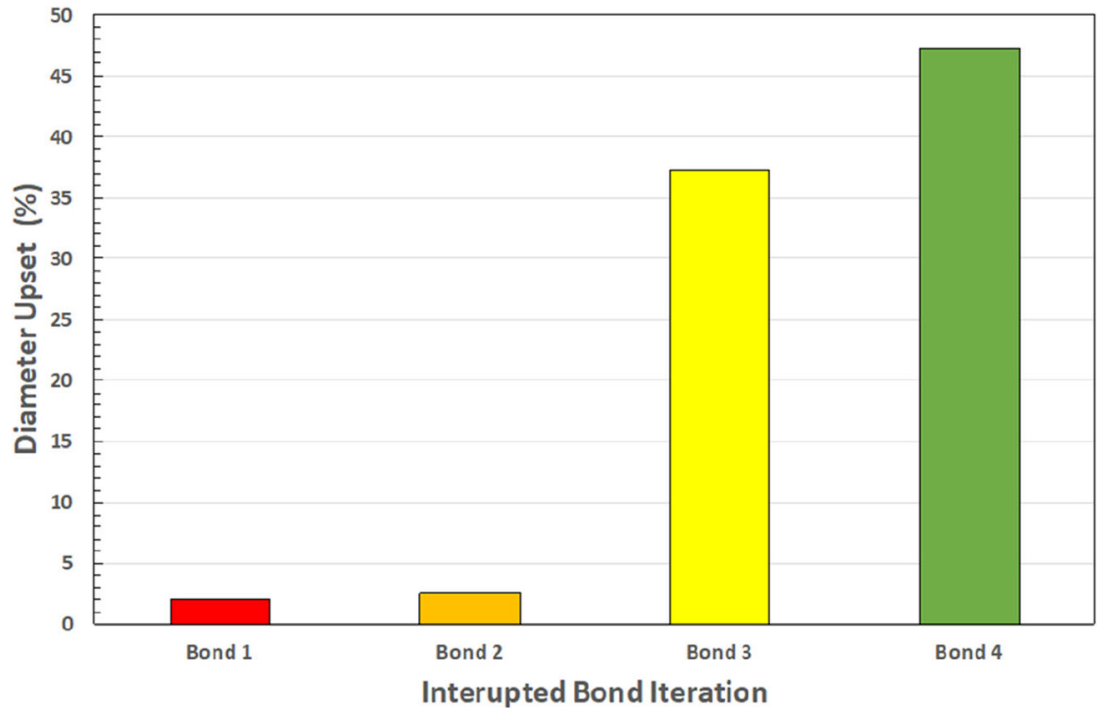


Table 2 Length and diameter upset by bond iteration

\begin{tabular}{lll}
\hline & Length upset $(\%)$ & Diameter upset $(\%)$ bond 1 \\
\hline Bond 1 & -0.13 & 2 \\
Bond 2 & -0.05 & 2.5 \\
Bond 5 & 4.95 & 37.2 \\
Bond 4 & 7.21 & 47.2 \\
\hline
\end{tabular}

HIPing appears to give more uniform microstructures and mechanical properties in components, but at a higher processing cost than diffusional bonding processes, this trade-off could also be considered one of quality vs cost.

\section{Experimental}

The present study utilised Ti 6-4 alloy (Ti-6Al-4V) specimens machined to the required geometry from billet materials supplied by Rolls-Royce plc. The chosen geometry consisted of two 10-mm bars of 65-mm length with mated 'cup and cone' bonding surface for bonding, such that the maximum dishing height protruded $2 \mathrm{~mm}$ above and below the specimen shoulder. Figure 2 shows a schematic of the specimen geometry.

Specimen interlayers were produced from gas atomised $\mathrm{Ti}$ 6-4 produced by LPW Technologies Ltd with powder particles having a diameter between 15 and $45 \mu \mathrm{m}$ (Fig. 3) and applied by 'wetting' the dished surface with glycerol and lightly dipping in powder such that a thin interlayer is transferred onto the specimen. Any excess was then carefully removed from the specimen edge, and glycerol was allowed to evaporate fully before bonding commenced. N-type thermocouples were applied to the 'cone'-type specimen by spot welding within $1 \mathrm{~mm}$ of the specimen mating surfaces and were used to control the heat application during the bonding process through use of a PID control system accurate to $1{ }^{\circ} \mathrm{C}$. Prior to the application of thermocouples and powder interlayers, both specimens were thoroughly cleaned in industrial acetone.

The two bonding specimens were fixed into the load train of an electric screw mechanical test frame using collets attached to the tails of each specimen and brought into contact under a holding compression force of $0.1 \mathrm{kN}$. These were then heated at $5^{\circ} \mathrm{C} \cdot \mathrm{s}^{-1}$ to the bonding temperature $\left(940^{\circ} \mathrm{C}\right)$ under argon shielding to prevent oxidation at the bonding temperature. Heating was achieved using a two-turn water-cooled copper induction coil around the specimen, such that the interlayer was located at the centre of the induced field. At the completion of each test, each bonded specimen was air cooled to room temperature before being removed and measured in terms of its new gauge length and diameter at three points using a calibrated micrometre. The bonded specimens were cut, were mounted in conductive Bakelite and underwent standard polishing procedures. Finally, all bonds were examined using back-scattered electron imaging on a scanning electron microscope equipped with electron back-scattered diffraction (EBSD). The images were collected at ten evenly spaced intervals of $1 \mathrm{~mm}$ each across the interlayer region at $250 \mathrm{x}$ magnification and a region consisting of only the interlayer region cropped and manipulated in 'ImageJ' software. Using the 'threshold' function to select the pores and the 'measure' function to measure their relative area, the consolidation of the interlayer region in terms of its fully dense volume fraction was assessed. Additionally EBSD mapping was performed as close as possible to the bond centres using a step size of 0.5 $\mu \mathrm{m}$, in order to understand any textural changes resulting from the bonding process, as well as deformation and recrystallisation mechanics. From previous work carried out at Swansea University, a standard bonding procedure for this material has been typically characterised by heating in the $\alpha+$ $\beta$-region to $940{ }^{\circ} \mathrm{C}$ at a holding force of $0.2 \mathrm{kN}$ at $5{ }^{\circ} \mathrm{C} \cdot \mathrm{s}^{-1}$. A bonding force of $3.2 \mathrm{kN}$ is then applied for $2 \mathrm{~min}$, followed by a diffusional period of $0.2 \mathrm{kN}$ for $30 \mathrm{~min}$ at the same
Fig. 7 Graph detailing powder interlayer thickness variation after each bond iteration

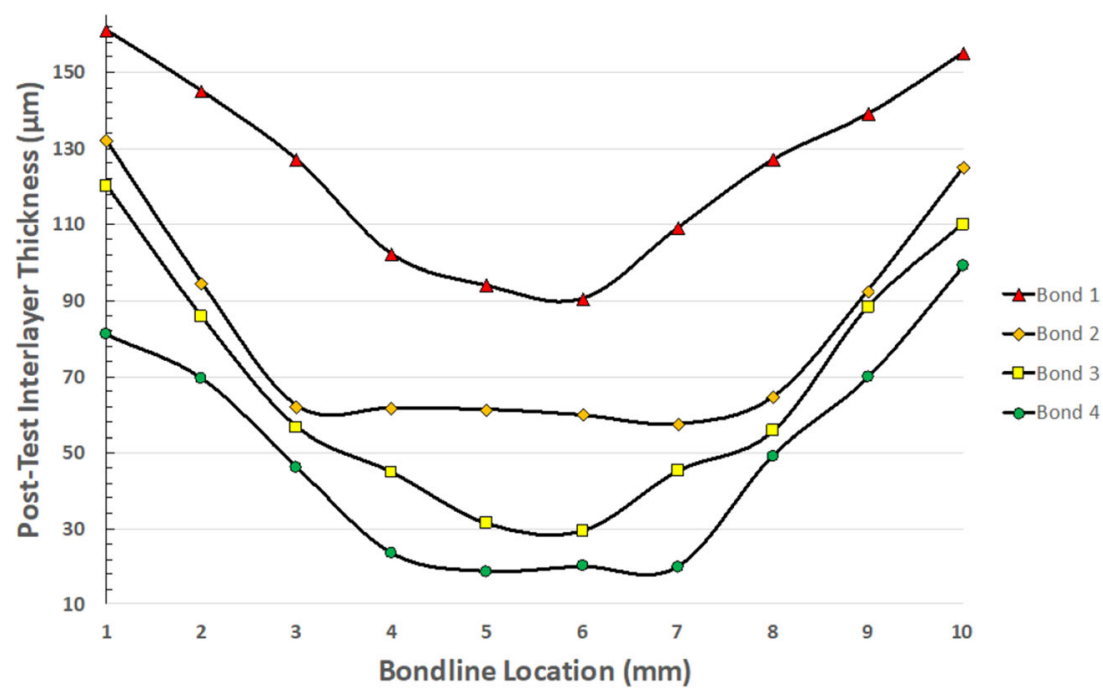


Fig. 8 Graph detailing powder interlayer porosity variation after each bond iteration

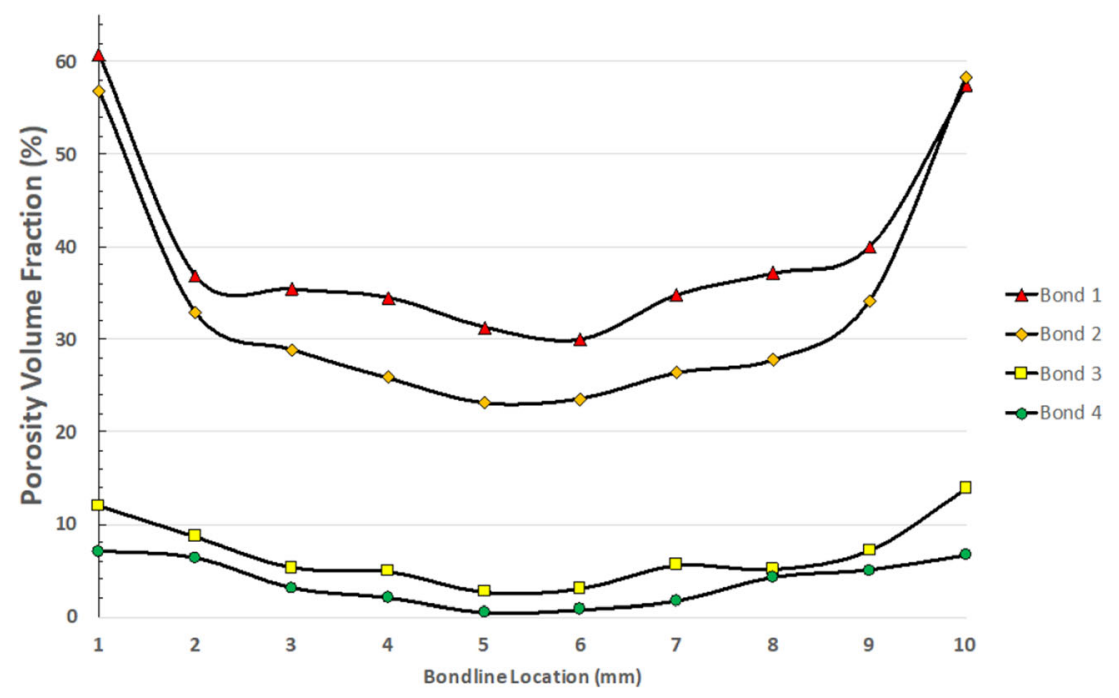

temperature. Force application is applied at a fixed rate of 0.5 $\mathrm{kN} \cdot \mathrm{s}^{-1}$. As this work only concerns the powder collapse mechanics during the early stages of this cycle, four bonds have been undertaken in order to assess this. These are shown below in Table 1.

\section{Results and Discussion}

The original microstructure of the Ti 6-4 billet material used for this work is shown in Fig. 4. This was found to have an equiaxed grain structure with $57 \%$ retained $\beta$ found at the triple point site between $\alpha$-grains. The average sizes of the grains were found to be $\sim 31.5$ and $12 \mu \mathrm{m}$, respectively, which is typical of previous billet material received by this processing route historically [19]. This is typical of Ti 6-4 material produced for the purposes of fan and compressor blade manufacture. Since this process is intended for exploitation as a repair technique for these components, it is important to preserve this microstructure and its associated properties as much as possible.

Due to the application of tensile compression force during the bonding process at temperature, the bulk of the material was found to exhibit a certain amount of plastic deformation in the bonded condition. This was measured as percentage

Table 3 Interlayer porosity area by bond iteration

Interlayer porosity by area $(\%)$

$\begin{array}{llllllllll}1 & 2 & 3 & 4 & 5 & 6 & 7 & 8 & 9 & 10\end{array}$

$\begin{array}{lllllllllll}\text { Bond 1 } & 60.7 & 36.8 & 35.4 & 34.5 & 31.3 & 29.9 & 34.8 & 37.1 & 39.9 & 57.4\end{array}$

$\begin{array}{lllllllllll}\text { Bond } 2 & 56.8 & 32.9 & 28.9 & 25.8 & 23.1 & 23.6 & 26.4 & 27.8 & 34.1 & 58.3\end{array}$

$\begin{array}{lllllllllll}\text { Bond } 3 & 12.0 & 8.6 & 5.3 & 4.9 & 2.6 & 3.0 & 5.6 & 5.1 & 7.1 & 13.8\end{array}$

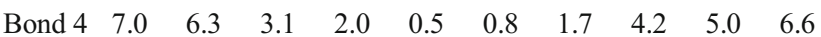

upset in length and diameter, respectively, calculated by Eq. 1 (where $\varepsilon_{\rho}$ is the degree of upset and $l_{o}$ and $l_{f}$ are the original and final length, respectively):

$\varepsilon_{\rho}=\frac{l_{o}-l_{f}}{l_{o}}$

While the upset associated with this process would mean that repaired components produced in this way would no longer conform to their original design, extra material can be added to the component via this technique, such that enough material can allow a final machining of the component to its original shape and specification. The data for bond 1 and bond 2 shows a slight elongation due to thermal expansion of $\sim 0.1 \%$, after the application of the $3.2 \mathrm{kN}$ bonding force in bonds 3 and 4 , length upset rose to 4.85 and $7.21 \%$ after $10 \mathrm{~s}$ and $20 \mathrm{~s}$ at the bonding force, respectively. A similar trend was also found in the examination of diameter upset, which rose from $2 \%$ in bond 1 to $37.2 \%$ after $10 \mathrm{~s}$ of force in bond 3 and $47.2 \%$ in bond 4 after $20 \mathrm{~s}$ at the same force. The diametric deformation exhibits itself as a 'barrelling' effect in the localised region heated in the field of the induction coil. The progression of both these deformation types during the bonding cycle is shown in Figs. 5 and 6, along with their respective values shown in Table 2 . These show the expected correlation between the 'barrelling' and length reduction effects after the application of the $3.2 \mathrm{kN}$ force.

The barrelling effect may prove helpful in that it naturally produces a larger volume of material in the immediate vicinity of the bond region. This means that any components repaired using this method could be easily machined back to original specification, allowing the defects that are observed at the edges of repaired coupons to simply be machined away, leaving only the region of highest integrity. With respect to the complex geometry of the mated bonding surfaces, both interlayer thickness and porosity were found to vary in each of the 

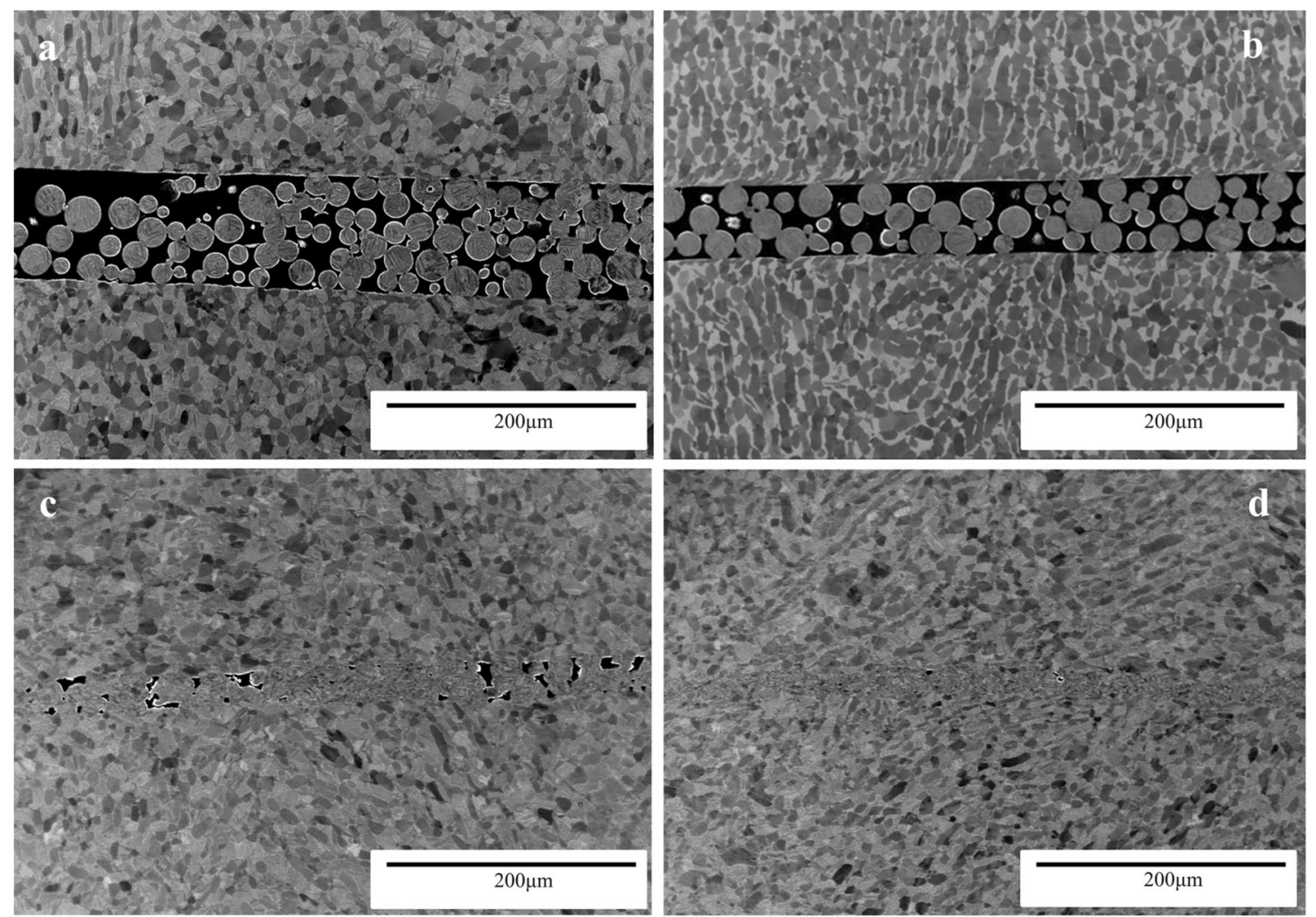

Fig. 9 SEM BSE micrographs of interrupted bond centres (a) bond 1, (b) bond 2, (c) bond 3 and (d) bond 4

interrupted bonds. In bond 1 , which was heated to $850{ }^{\circ} \mathrm{C}$ under a $0.2-\mathrm{kN}$ holding force, interlayer thickness fell from $\sim 160 \mu \mathrm{m}$ at the bond edge to $\sim 90 \mu \mathrm{m}$ at the bond centre as a result of the holding force at elevated temperature. This effect was exaggerated in bond 2 by the increased temperature of $940{ }^{\circ} \mathrm{C}$ at the same force, with interlayer thickness falling to $\sim 130$ and $\sim 60 \mu \mathrm{m}$ at the edge and centre, respectively. A dramatic effect in the consolidation of the applied interlayer was seen after the initial 10-s application of the bonding force in bond 3, which saw the interlayer reduce to $\sim 115 \mu \mathrm{m}$ at the edge and $\sim 30 \mu \mathrm{m}$ at the centre. A further $10 \mathrm{~s}$ at the bonding force produced a final interlayer thickness at the edge and centre of $\sim 90$ and $\sim 20 \mu \mathrm{m}$, respectively. The relatively quick collapse and consolidation of these interlayers are an attractive prospect with regards to the implementation of this technique as a repair process. Pore degassing and closure appear to complete very quickly after the application of the bonding force, providing scope for streamlining of specific component repairs, to allow shortened timescales and costs involved with these complex repairs. In theory repair times could be adjusted according to the properties required for individual applications.

Figure 7 shows how interlayer thickness across the bondline was affected by the various iterations of the interrupted bond cycle. This gradual reduction in the interlayer thickness through the bonding cycle is a function of the degassing of the pores between the powder particles, which make up the interlayer. Initially, between bonds 1 and 2, this appears to be temperature dependent, which could result from deformation and flow of the powder particles under the holding force, allowing for better packing. In bonds 2 and 3, this effect is not only exaggerated by the introduction of the bonding force but also magnified as excess powder is flushed towards the edge of the specimen as the force increases. This effect shows that powder geometries are extremely important with regard to the consolidation of the interlayer region, as the flow of these powders determines their repacking potential, as well as the contact area available for diffusion. In order to maximise the final bond integrity and minimise interlayer thickness, it appears that highly spherical powder would be the most favourable for use in this process, as particles will have more effective flow and enhanced packing potential.

In a traditional bonding cycle, the increased time at the bonding force diffusional period allows further degassing of pores and sintering of metallic powder to allow near-full densification of the interlayer region. This was shown by the porosity volume fraction of the interlayer shown in Fig. 8 and corresponding Table 3. Similar to interlayer thickness, porosity volume fraction reduced from $\sim 60 \%$ at the edge to $\sim 30 \%$ at the centre of bond 1 at $850{ }^{\circ} \mathrm{C}$, which fell to $\sim 23 \%$ at the centre of bond 3 after the temperature was increased to 940 ${ }^{\circ} \mathrm{C}$, although only a small effect was seen at the edge.

This is likely due to the powder flushing and packing effect previously described. After the application of the bonding 
Fig. 10 Inverse pole figure maps (IPF) for (a) bond 1, (b) bond 2,

(c) bond 3 and (d) bond 4

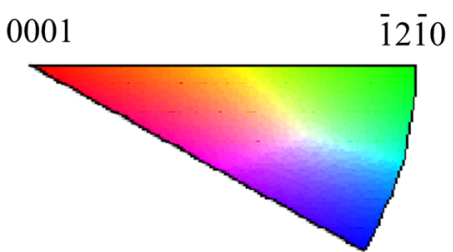

$01 \overline{10}$
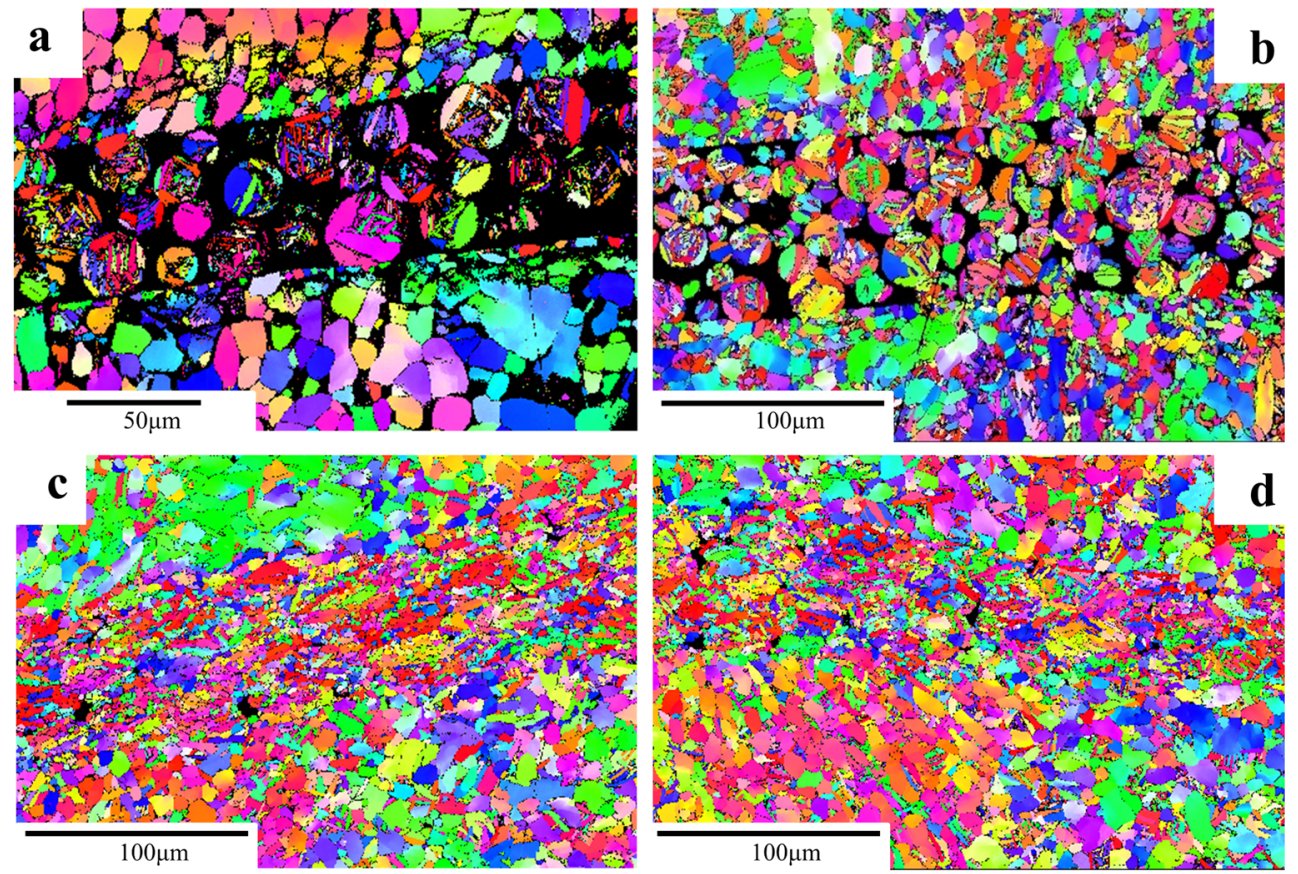

force, subsequent deformation at the specimen edge allowed porosity to fall to $\sim 11 \%$ at the shoulder and $3 \%$ at the bond centre of bond 3 . Increasing the duration of the force to $20 \mathrm{~s}$ in bond 4 allowed a small reduction in porosity to $7 \%$ at the edge and a considerable reduction to $\sim 0.5 \%$ at the bond centre. Although not examined here, completion of the full bond cycle of $2 \mathrm{~min}$ at $3.2 \mathrm{kN}$ followed by a diffusional period at 0.2 $\mathrm{kN}$ can result in near-full consolidation of the interlayer region, with very limited porosity.

It should be noted that in all bonds, interlayer thickness, porosity distribution and size were found to increase at the specimen edge due to powder flushing and the more aggressive geometric effect in this region. In terms of repair applications for this bonding process, this slight increase in porosity at the specimen edges may not be a major issue, as this region would be machined off post bonding. In consideration of this process's exploitation in the repair of cyclically loaded components, the minimisation of any defects in the repaired microstructure is crucial in order to preserve strength and fatigue properties. These results are extremely promising in this context, as the regions containing the most porosity are located towards the specimen edge, and could easily be machined away during the final preparations of the component before re-entry into service. The porosity observed at the centre of powder interlayer-bonded components which have undergone the full bond duration is well within the maximum tolerances for repaired components of this type.

Examination of the resultant microstructures at the bond centres revealed only partial sintering of powder particles at the bond centres of bonds 1 and 2, likely due to their limited duration at the bonding temperature and limited force application. Examination of bonds 3 and 4 after the introduction of the bonding force shows the effect of this mechanical energy in the degassing and sintering of the interlayer region, and clear microstructural regions resultant of effective diffusion bonding can be seen particularly in bond 4 . This is to be expected given this bond received the longest duration at both the bonding temperature and force. The fully sintered regions in the bondlines of bonds 3 and 4 showed refined grain size when compared to the base material, as expected, due to the refined geometry of the powder particles used in the interlayer region. This refined structure could prove useful in the maintenance of fatigue and strength properties of future components which could be repaired by this technique; however, work is required in order to examine how this may affect the ductility. Further 

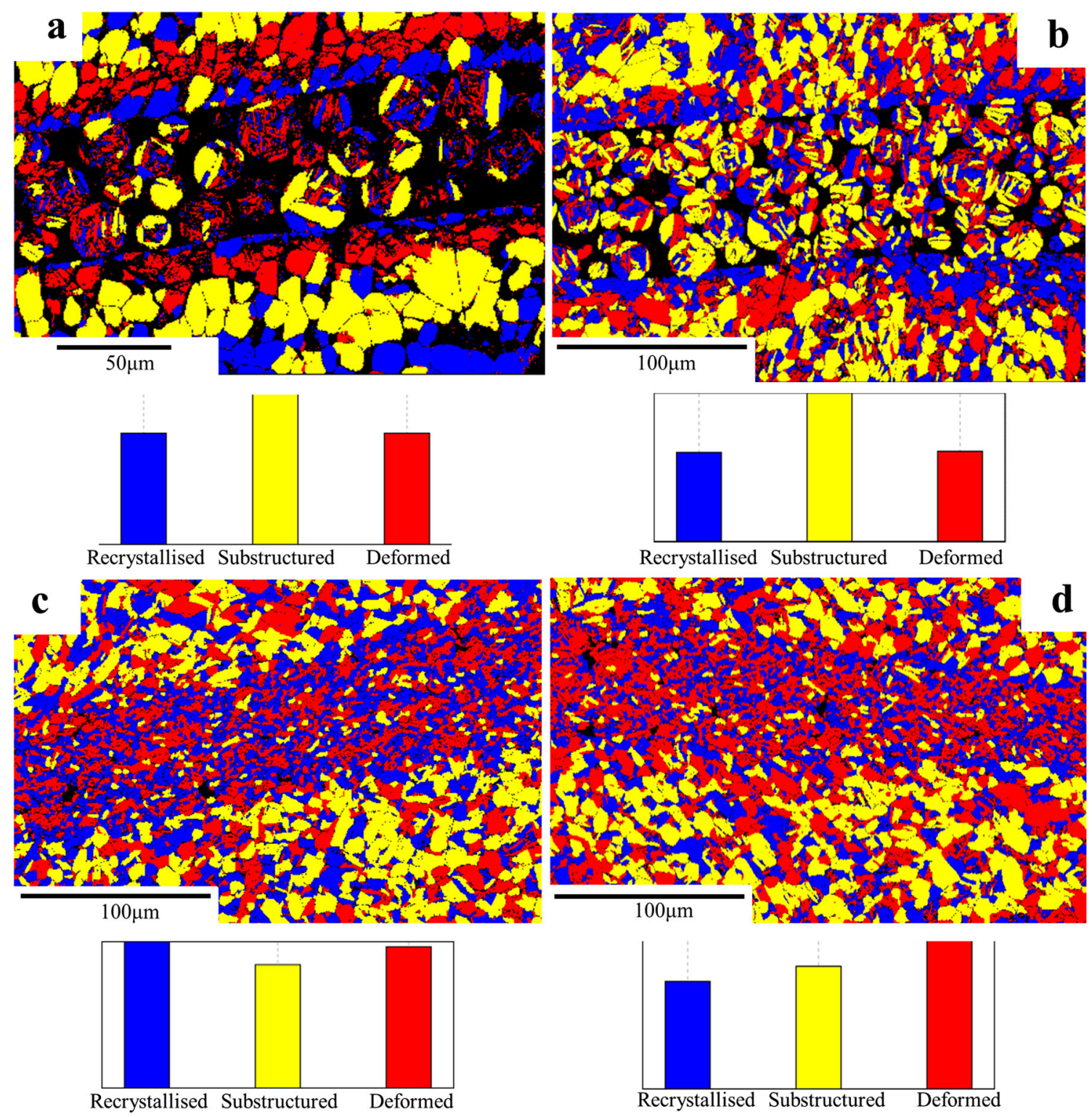

Fig. 11 Recrystallised fraction maps for (a) bond 1, (b) bond 2, (c) bond 3 and (d) bond 4

work will also be required to examine the macro effect of this refinement on the mechanical properties of complex geometric bonding surfaces, as well as the textural effects resulting from the deformation of the powder particles and bulk specimen during the bonding process. Micrographs of all four bond centres are shown in Fig. 9.

Textural mapping of all four bonds appears to show no obvious textural effects resulting from the bonding parameters during the early stages of collapse as seen in Fig. 10. However, in Fig. 11, bonds 1 and 2 seem to show an increased volume of deformed and recrystallised grains at the bond centre, likely resulting from the thermal expansion associated with the temperature increase from 850 to 940
${ }^{\circ} \mathrm{C}$, as well as the increased proximity to the $\beta$-transus. After application of the bonding force of $3.2 \mathrm{kN}$ for $10 \mathrm{~s}$ in bond 3 , we see an increase in the amount of recrystallisation of the powder particles at the bond centre, as well as some recrystallised material. Finally, after $20 \mathrm{~s}$ at the $3.2-\mathrm{kN}$ bonding force, the recrystallised material begins to deform as the last of the pores degas from the interlayer region. These effects could promise for microstructural manipulation of components repaired by these methods in situ. By manipulating the bonding temperature and forces used in the process, additional steps could be added to allow thermal-mechanical processing of the interlayer region itself to achieve the desired microstructure and properties. 


\section{Conclusions}

The following conclusions were drawn from the present programme of research:

- Increasing the bonding temperature from 850 to $940{ }^{\circ} \mathrm{C}$ under the same holding force can allow partial sintering of the powder interlayer, as well as some flushing and rearranged packing resulting in interlayer and porosity area refinement at the bond centre only.

- Introduction of increased compressional load exaggerates the packing effect, allowing more effective degassing of these pores, as well as initial sintering of metallic powder particles at both the centre.

- The interlayer thickness and porosity refinement at the edge appear to be assisted by the plastic deformation of the bulk specimens at the most aggressive geometric location.

- Increased duration at the bonding force and temperature further exaggerates these effects and given the correct parameters can result in, at the very least, regions of fully densified interlayers which improve towards the central loading axis of the bond. This is likely aided by the less severe geometry at the bond centre.

- Bonding energy inputs in the form of heat and pressure appear to promote recrystallisation at the interlayer region when combined; however, individually this can lead to deformed material with some substructure.

- Further work is required to understand the textural and mechanical property effects of changing microstructure of the bonded components in order to streamline for industrial application.

Acknowledgements The provision of a research bursary to IW, materials and supporting information from Rolls-Royce plc is gratefully acknowledged. Mechanical tests were performed at Swansea Materials Research and Testing Ltd. (SMaRT).

Funding information The current research was funded by the Materials and Manufacturing Academy (M2A) supported by the European Social Fund through the Welsh Government.

Open Access This article is licensed under a Creative Commons Attribution 4.0 International License, which permits use, sharing, adaptation, distribution and reproduction in any medium or format, as long as you give appropriate credit to the original author(s) and the source, provide a link to the Creative Commons licence, and indicate if changes were made. The images or other third party material in this article are included in the article's Creative Commons licence, unless indicated otherwise in a credit line to the material. If material is not included in the article's Creative Commons licence and your intended use is not permitted by statutory regulation or exceeds the permitted use, you will need to obtain permission directly from the copyright holder. To view a copy of this licence, visit http://creativecommons.org/licenses/by/4.0/.

\section{References}

1. Whittaker M (2011) Titanium in the gas turbine engine. Advances in gas turbine technology. InTech, In, pp 315-336

2. Inagaki I, Tsutomu T, Yoshihisa S NA (2014) Application and features of titanium for the aerospace industry

3. Veiga C, Loureiro AJRDJP (2012) Properties and applications of titanium alloys. Rev Adv Mater Sci 32:133-148

4. Lütjering $G$ (1998) Influence of processing on microstructure and mechanical properties of $(\alpha+\beta)$ titanium alloys. Mater Sci Eng A 243:32-45. https://doi.org/10.1016/S0921-5093(97)00778-8

5. Ding R, Guo ZX, Wilson A (2002) Microstructural evolution of a Ti-6Al-4V alloy during thermomechanical processing. Mater Sci Eng A 327:233-245. https://doi.org/10.1016/S0921-5093(01) 01531-3

6. Eylon D, Fujishiro S, Postans PJ, Froes FH (1984) Hightemperature titanium alloys - a review. JOM 36:55-62. https:// doi.org/10.1007/BF03338617

7. TIMETAL 6-4, 6-4 ELI \& 6-4-.1Ru Medium to high strength general purpose alloys, data sheet. http://www.timet.com/assets/local/ documents/datasheets/alphaandbetaalloys/6-4.pdf

8. Lütjering G (2007) Alpha + beta alloys. In: Titanium. Springer, Berlin Heidelberg, Berlin, Heidelberg, pp 203-258

9. Properties and processing of TIMETAL 6-4, TIMET brochure. http://www.timet.com/assets/local/documents/datasheets/ alphaandbetaalloys/6-4.pdf

10. García A (2011) BLISK fabrication by linear friction welding. In: Benini E (ed) Dr. Advances in gas turbine technology, InTech, pp 411-435

11. Peters M, Kumpfert J, Ward CH, Leyens C (2003) Titanium alloys for aerospace applications. Adv Eng Mater 5:419-427. https://doi. org/10.1002/adem.200310095

12. Kumar BVRR (2013) A review on blisk technology. Int J Innov Res Sci Eng Technol 2:1353-1358

13. Messler RW (2002) Fusion welding processes. In: Principles of welding. Wiley-VCH Verlag GmbH, Weinheim, Germany, pp 4093

14. Messler RW (2007) Thermally induced distortion and residual stresses during welding. In: Principles of welding. Wiley-VCH Verlag GmbH, Weinheim, Germany, pp 181-215

15. Fitzpatrick GA, Broughton T (1988) Diffusion bonding aeroengine components. Def Sci J 38:477-485

16. Çam G., Clemens H., Gerling R., and Koçak M.: Diffusion bonding of fine grained gamma-TiAl sheets, Z. Metallkd., 1999, Vol. 90 (Iss. 4), pp. 284-288

17. Çam G, Müllauer J, Koçak M (1997) Diffusion bonding of two phase $\gamma$-TiAl alloys with duplex microstructure. Sci Technol Weld Join 2(5):213-219. https://doi.org/10.1179/stw.1997.2.5.213

18. Koçak M, Pakdil M, Cam G (2002) Fracture behaviour of diffusion bonded Ti-alloys with strength mismatch. Sci Technol Weld Join 7(4):187-196. https://doi.org/10.1179/136217102225004220

19. Çam G, Özdemir U, Ventzke V, Koçak M (2008) Microstructural and mechanical characterization of diffusion bonded hybrid joints. $\mathrm{J}$ 
Mater Sci 43(10):3491-3499. https://doi.org/10.1007/s10853-0072403-2

20. Çam G, Koçak M, Dobi D, Heikinheimo L, Siren M (1997) Fracture behaviour of diffusion bonded bimaterial Ti-Al joints. Sci Technol Weld Join 2(3):95-101. https://doi.org/10.1179/stw. 1997.2.3.95

21. Çam G, Bohm K-H, Müllauer J, Koçak M (1996) The fracture behavior of diffusion-bonded duplex gamma TiAl. JOM, The Journal of the Minerals, Metals and Materials Society 48(11):66-68

22. Çam G., İpekoğlu G., Bohm K.-H, and Koçak M. Investigation into the microstructure and mechanical properties of diffusion bonded TiAl alloys, J Mater Sci, 2006, Vol. 41 (Iss. 16; Special Issue: Interfaces by Design), pp. 5273-5282 https://doi.org/10.1007/ s10853-006-0292-4

23. Lee H-S, Yoon J-H, Park CH et al (2007) A study on diffusion bonding of superplastic Ti-6Al-4V ELI grade. J Mater Process Technol 187-188:526-529. https://doi.org/10.1016/j.jmatprotec. 2006.11.215

24. Flower HM (1995) High Performance materials in aerospace. Springer Netherlands, Dordrecht

25. Messler RW (2004) Nonfusion welding processes. In: Principles of welding. Wiley-VCH Verlag GmbH, Weinheim, Germany, pp 94 123
26. Davies P, Johal A, Davies H, Marchisio S (2019) Powder interlayer bonding of titanium alloys: Ti-6Al-2Sn-4Zr-6Mo and Ti-6Al-4V. Int J Adv Manuf Technol 103:441-452. https://doi.org/10.1007/ s00170-019-03445-3

27. Tuppen SJ, Bache MR, Voice WE (2006) Structural integrity of diffusion bonds in Ti-6Al-4V processed via low cost route. Mater Sci Technol 22:1423-1430. https://doi.org/10.1179/ 174328406 X129922

28. Tuppen SJ, Bache MR, Voice WE (2005) A fatigue assessment of dissimilar titanium alloy diffusion bonds. Int J Fatigue 27:651-658. https://doi.org/10.1016/j.ijfatigue.2004.11.004

29. Li P, Warner DH, Pegues JW, Roach MD, Shamsaei N, Phan N (2019) Investigation of the mechanisms by which hot isostatic pressing improves the fatigue performance of powder bed fused Ti-6Al-4V. Int J Fatigue 120:342-352. https://doi.org/10.1016/j. ijfatigue.2018.10.015

Publisher's note Springer Nature remains neutral with regard to jurisdictional claims in published maps and institutional affiliations. 